\title{
RACISMO MODERNO Y POSTMODERNO EN EUROPA: ENFOQUE DIALÓGICO Y PEDAGOGÍAS ANTIRRACISTAS*
}

\section{Ramón Flecha}

Universidad de Barcelona

\begin{abstract}
RESUMEN
En este artículo se plantea el incremento del racismo en la Europa actual y los retos que este hecho plantea para la educación y los y las educadoras. El autor distingue entre dos tipos de racismo: uno antiguo, el racismo moderno, y otro más reciente, el racismo postmoderno. El primero está basado en argumentos de desigualdad y en la existencia de razas y etnias superiores e inferiores. El segundo mantiene que las etnias y las razas no son ni superiores ni inferiores; son simplemente diferentes. Pone el énfasis en la imposibilidad de un diálogo igualitario entre razas y etnias diferentes para establecer normas comunes de convivencia. A pesar de que en Europa existe una tradición educativa antirracista, los y las educadoras a menudo no tienen los instrumentos intelectuales y educativos para combatir esta forma de racismo. Flecha sugiere que los y las educadoras han intentado combatir el racismo desarrollando pedagogías antirracistas que utilizan el enfoque relativista defendido por pensadores contemporáneos como Michel Foucault y Jacques Derrida. El autor argumenta que este enfoque supone un reto para el racismo moderno pero que en realidad promueve el racismo postmoderno. Partiendo de los trabajos de teóricos dialógicos como Paulo Freire y Jürgen Habermas, Flecha recomienda, en cambio, que los y las educadoras utilicen el enfoque dialógico, el cual pone el énfasis en la necesidad de la igualdad de derechos para todas las personas, para desarrollar así pedagogías antirracistas eficaces que puedan combatir de forma simultánea ambas formas de racismo.
\end{abstract}

* Traducción del artículo original: Ramón FleCHA, «Modern and Postmodern Racism in Europe: Dialogic Approach and Anti-Racist Pedagogies», Harvard Educational Review, 69: 2, pp. 150-171. Copyright (C) 1999 by the President and Fellows of Harvard College. All rights reserved. 
El Consejo de la Unión Europea declaró 1997 como el «Año Europeo contra el Racismo" con el objetivo de concienciar al público en general sobre una nueva ola de racismo emergente en Europa. En reconocimiento de esta declaración, muchas escuelas europeas han desarrollado e implementado nuevas pedagogías dirigidas a la eliminación del racismo. De cualquier modo, y a pesar de todos sus esfuerzos, el racismo continúa manifestándose en nuevas y alarmantes formas. En respuesta a este hecho, los y las educadoras e intelectuales se han ocupado de reflexionar en profundidad acerca de cómo desarrollar mejores programas y políticas que contrarresten este temor con relaciones educativas pacíficas.

Una de las debilidades de los actuales programas educativos y de las políticas antirracistas es su frecuente confusión entre los enfoques dialógico y relativista. El enfoque dialógico promueve la convivencia entre personas diferentes en base a reglas consensuadas entre todos y todas a través del diálogo libre e igualitario. En contraposición, el enfoque relativista rechaza tales reglas argumentando que éstas eliminan las identidades y diferencias de quienes están oprimidos. Este artículo pretende clarificar las diferencias entre los enfoques relativista y dialógico en la literatura educativa y entre sus respectivas consecuencias en relación a viejas y nuevas formas de racismo. Las viejas, las formas modernas de racismo, están basadas en argumentos de desigualdad entre las razas y en la existencia de razas superiores e inferiores. Las más recientes, las formas postmodernas de racismo, hacen hincapié en la diferencia entre etnias y razas en vez de en la igualdad. Las dos primeras partes de este artículo describen la manera en que las nuevas formas de racismo desafían la educación europea y argumentan la necesidad de incluir el enfoque dialógico en la educación para superar el racismo. La argumentación se construye sobre las definiciones del racismo moderno y postmoderno y describe cómo ambos coexisten actualmente en Europa. Pone de relieve el hecho de que, a pesar de que existe una tradición moderna antirracista en Europa, los instrumentos intelectuales y educativos actualmente en uso son insuficientes para combatir el racismo postmoderno. Demuestra, además, que algunos conceptos utilizados en la lucha contra el racismo moderno - conceptos relacionados con la diferencia y la identidad- promueven en realidad el racismo postmoderno al no incluir la idea de igualdad.

La tercera parte argumenta que el racismo moderno viene generado principalmente por creencias etnocentristas y desarrolla las tres características principales del etnocentrismo como base intelectual del racismo moderno. La cuarta sección analiza la relación entre el racismo postmoderno y sus bases postestructuralistas, desarrollando las tres principales características del relativismo como base intelectual del racismo postmoderno. Plantea también cuestiones cruciales para las y los educadores, analizando hasta qué punto autores como Jacques Derrida, Michel Foucault y Martin Heidegger son, a menudo, tergiversados en la literatura educativa. La última sección desarrolla las tres principales características del enfoque dialógico, centrándose en cómo este enfoque difiere de los otros. Parte de las teorías sociales y educativas de autores como Jürgen Habermas y Paulo Freire e incluye ejemplos de prácticas educativas que confrontan tanto el racismo moderno como el postmoderno. 


\section{LOS RETOS DEL NUEVO RACISMO PARA LA EDUCACIÓN EUROPEA ACTUAL}

La declaración del «Año Europeo contra el Racismo» estuvo justificada por el auge del racismo en la sociedad europea y, en particular, por el rápido incremento del neonazismo en los noventa. En Austria, el partido neonazi $F P \ddot{O}^{1}$ quedó segundo en las últimas elecciones generales de 1999, con un 26\% de los votos, y formó gobierno con el ÖVP, que había quedado tercero. El Frente Nacional de Jean-Marie Le Pen ganó el 15,1\% de los votos en las elecciones presidenciales de 1995. En la Bélgica flamenca, en las elecciones comunales y provinciales de octubre del 2000, el también neonazi Vlaams Block logró uno de cada tres votos en Amberes. En 1997, en Noruega, el neonazi Fremskrittspartiet quedó segundo en las elecciones generales presidenciales, con el 15,3\% de los votos. También en 1997, el neonazi Vojislav Seselj, un sociólogo que fue el primero en hablar de purificación étnica en la guerra de Bosnia, ganó el 50\% de los votos en la segunda vuelta de las elecciones en Serbia.

Estas ideologías también influyen en lo que la juventud europea hace y cree. En 1991, el gobierno austríaco lanzó una campaña contra el uso de un juego para adolescentes en el que los jugadores ganaban puntos por enviar a la cámara de gas a judíos, gays y lesbianas. En 1998, en Viena, el 20\% de los adolescentes encuestados se declaró cercano a la extrema derecha, y el 58\% declaró que apoyaría la idea de una persona fuerte que tomara el poder e impusiera el orden (Cáceres, 1993). Los efectos de estas ideologías en la juventud europea retaron directamente a los y las educadoras a desarrollar nuevos programas y nuevas políticas para hacer frente a estos problemas, pero están inseguros acerca de cómo valorar el alarmante incremento del racismo. En la búsqueda de soluciones, las y los educadores a menudo han adoptado programas que, más que eliminar el racismo, lo han exacerbado. Hoy, por ejemplo, muchos educadores y educadoras europeos hacen hincapié en la idea de la diversidad como una forma de oponerse a las cada vez más numerosas creencias en la superioridad o inferioridad de determinadas razas o etnias.

No son conscientes de que quienes mantienen creencias racistas, como los grupos neonazis previamente citados, también utilizan el concepto de la diferencia para sostener sus programas de odio. Centrarse en la diferencia y la diversidad, al mismo tiempo que se excluye la idea de igualdad, oscurece la posibilidad de la solidaridad y enmascara la posibilidad de la convivencia en un mismo espacio y de compartir las mismas instituciones educativas.

Las y los educadores deben clarificar esta falta de conciencia si tienen que desarrollar instrumentos efectivos para la lucha contra el racismo. Existe un esfuerzo de clarificación emergente arraigado en las perspectivas dialógicas

${ }^{1}$ El líder del FPÖ, Joerg Haider, es ahora el líder imperante en el neonazismo europeo. Haider considera Austria parte de la Gran Alemania y tuvo que dimitir como presidente del gobierno regional de Carintia tras proponer y tratar de aplicar la misma política de empleo que el Tercer Reich alemán. 
desde las que los y las intelectuales de la actualidad contribuyen al desarrollo de nuevas pedagogías antirracistas. Los trabajos de autores como Habermas y Freire están orientados a la combinación de la igualdad y la diferencia y, por lo tanto, ofrecen un marco alternativo que significa un reto tanto para el etnocentrismo como para el relativismo, bases del actual racismo europeo. Desde esta perspectiva, las y los educadores antirracistas brindan su apoyo, por ejemplo, a las mujeres gitanas que reivindican tanto el derecho a la educación como el derecho a decidir qué tipo de educación respetaría sus identidades. Este modo de pensar reemplaza la idea de que "somos diferentes» por la idea de que «somos iguales y somos diferentes».

Esta clarificación requiere que nos comprometamos en un estudio en profundidad de los autores clave de la perspectiva dialógica y de la relativista. Gran parte de la literatura educativa sobre racismo utiliza los trabajos de autores como Foucault o Habermas, pero sus artífices a menudo no han leído dichos textos de primera mano. A menudo citan estos autores indirectamente, sin ninguna notación de sus trabajos, bibliografía o páginas ${ }^{2}$. En suma, citan fuentes secundarias en lugar de las primarias. Haciendo esto, extienden sus propias confusiones a otros educadores y educadoras, quienes posteriormente desarrollan acciones antirracistas con buenas intenciones pero con orientaciones muy equivocadas.

\section{LA NECESIDAD DEL ENFOQUE DIALÓGICO EN LA EDUCACIÓN EUROPEA ACTUAL}

Europa ha sido un continente de emigración desde 1492; por lo tanto, las escuelas europeas históricamente han educado principalmente estudiantes europeos. Como resultado, hemos desarrollado teorías y prácticas educativas basadas en el supuesto de que la línea general de la cultura europea es la norma universal. Sólo en el siglo XX este proceso migratorio se ha convertido en uno de inmigración (Contreras, 1994).

Las escuelas europeas reflejan estos cambios. Como resultado de la inmigración, nuestras instituciones educativas están recibiendo un número creciente de personas procedentes de África y Asia. En España, por ejemplo, entre 1988 y 1997 el número total de inmigrantes legales aumentó un 69\%, pero la proporción de inmigrantes legales procedentes de Asia y África aumentó, den-

2 Malinterpretaciones de la literatura original han creado numerosos problemas en educación. Por ejemplo, en los setenta, el modelo de la reproducción de Althusser, tal y como fue desarrollado por sus seguidores Bourdieu-Passeron, Baudelot-Establet y Bowles-Gintis, aplicó el estructuralismo marxista a la educación. En Para leer El Capital (1985), Althusser creó el estructuralismo marxista, pero más tarde reconoció (Althusser, 1992) que había escrito este libro sin haber leído el Das Kapital de Marx. Una parte considerable de la literatura educativa acabó basándose en las malinterpretaciones de Althusser. El mismo proceso está sucediendo en la actualidad en la literatura educativa con autores como Foucault. 
tro de ese mismo porcentaje, un 298\%. La movilidad entre las poblaciones europeas en el seno de la Unión Europea también ha aumentado la composición multinacional de las escuelas. Éstas se han visto inundadas también de poblaciones inmigrantes como respuesta a los cambios sociales y políticos en la Europa del Este. Adicionalmente, los elevados índices de natalidad y el cambio de una vida nómada a otra sedentaria han incrementado la población gitana en las escuelas.

Como resultado de este nuevo ambiente multicultural, las y los europeos afrontan ahora el problema de aprender a convivir en los mismos territorios e instituciones educativas. La gente puede dar una respuesta a esta cuestión utilizando pretensiones de validez o pretensiones de poder como la base de sus acciones (Habermas, 1987b). Esencialmente, deben elegir entre la violencia y el diálogo (Giddens, 1996). Las pretensiones de poder imponen acciones a la gente, mientras que las pretensiones de validez buscan la base de un consenso para la acción a través de la argumentación. Los enfoques relativistas no diferencian entre estos dos tipos de pretensiones porque argumentan que cualquier pretensión está generada por el poder. En contraposición, el enfoque dialógico rechaza las pretensiones de poder y en su lugar promueve las pretensiones de validez.

El uso de las pretensiones de poder para orientar las acciones tiene como resultado la coexistencia, hoy día, del racismo moderno y postmoderno en Europa. El racismo moderno existe cuando las reglas de la cultura dominante son impuestas a pueblos diferentes en nombre de la integración. El racismo postmoderno existe cuando la gente niega la posibilidad del diálogo entre grupos diferentes y rechaza la posibilidad de coexistencia entre grupos diferentes dentro del mismo territorio. Hoy en día, los programas educativos y las políticas antirracistas combaten el racismo moderno y su idea de desigualdad racial, la cual es todavía muy poderosa en nuestras instituciones y en nosotros y nosotras mismas. Al mismo tiempo, muchos de estos programas educativos antirracistas promueven una seductora imagen del racismo postmoderno en espacios donde el racismo moderno ya ha sido claramente rechazado. Haciendo frente a los retos que plantean tanto el racismo moderno como el postmoderno, el enfoque dialógico trabaja para que la gente de diferentes etnias pueda convivir dentro del mismo sistema educativo en base a normas acordadas a partir del diálogo.

El racismo moderno reivindica la desigualdad entre las razas. Por ejemplo, el racismo occidental tradicional ha promovido la idea de que los payos son superiores a los gitanos. Considera que las desigualdades sociales y culturales son una consecuencia de las características biológicas de las personas, más que de las construcciones sociales y políticas de quienes detentan el poder. Desde la perspectiva del racismo moderno, los y las gitanas tienen menos éxitos educativos y posiciones sociales más bajas porque son más vagos o menos inteligentes, y no porque las escuelas sean instituciones payas y la comunidad gitana tenga menos poder en la educación y la sociedad (Presencia Gitana, 1991). 
El racismo moderno era característico de la sociedad europea industrial. En los sesenta, los y las inmigrantes eran canalizados hacia los trabajos peor pagados. El mercado laboral necesitaba personas de otras culturas para hacer aquellos trabajos que los ciudadanos medios consideraban indeseables y la idea de la desigualdad entre las razas legitimaba esta explotación. La explicación de que los bajos logros académicos de ciertas razas eran debidos a una inferior motivación e inteligencia justificó su posterior ubicación en posiciones de bajo status.

En las últimas décadas, esta idea de las desigualdades raciales ha sido contrarrestada y parcialmente desterrada por pedagogías antirracistas. Como resultado, los argumentos sobre la superioridad o inferioridad de una raza respecto a otra son erradicados de forma paulatina de la literatura educativa y de los currículums. La mayoría de las y los autores europeos (e.g., Molina, 1994) rechazan el concepto de raza, considerado como un concepto biológico inaplicable a la construcción social de las identidades humanas ${ }^{3}$. En Europa, clasificar las personas según la raza a menudo es asociado con la limpieza étnica. El Holocausto aún permanece amenazante en las mentes de muchos europeos y europeas y los acontecimientos de Kosovo nos advierten de que este tipo de sucesos pueden volver a darse. España, por ejemplo, prohíbe las definiciones de raza en cualquier documento oficial. En lugar del concepto de raza, numerosas minorías étnicas europeas y científicos y científicas sociales utilizan ahora el concepto de "procedencia étnica», un término que incluye tanto el aspecto cultural como el biológico de la identidad.

Muchos educadores y educadoras también se centran en las diferencias entre etnias. Hacen esto en una sociedad en la que la diferencia étnica se está convirtiendo rápidamente en la base de políticas racistas como resultado de las desigualdades sociales, políticas y económicas derivadas del salto de una sociedad industrial a una sociedad informacional (Castells, 1997a, 1997b, 1998). Esta transformación ha conducido a una escasez de puestos de trabajo estables. En esta economía cambiante, algunos europeos y europeas ven a los inmigrantes como potenciales competidores laborales y como una carga social para los presupuestos públicos. No quieren tratar otros grupos étnicos como subordinados pero quieren segregarlos de sus hijos e hijas, de su comunidad y de su país. Cuando los niños y las niñas de minorías étnicas suspenden, son culpados por la pobreza académica de sus colegios, y a veces lo es incluso el sistema educativo mismo; cuando tienen éxito, son considerados como «ladrones» de los escasos puestos de trabajo.

Quienes apoyan las barreras a la inmigración o incluso dan su apoyo a la expulsión de inmigrantes, han buscado nuevas formas de legitimar sus agendas ${ }^{4}$.

3 Este proceso se está dando también en relación al género, ya que cada vez un mayor número de autores está reemplazando el concepto biológico de sexo por el biológico-cultural de género.

${ }^{4}$ Las barreras como las cuotas anuales estrictas pretenden dificultar cada vez más la entrada en Europa. Diversas organizaciones por los derechos humanos han denunciado estas cuotas. Los 
El pensamiento postmodernista ha provisto el contexto intelectual para ello, permitiendo al nuevo racismo pasar de centrarse en la superación de las desigualdades raciales al reconocimiento de las diferencias culturales y étnicas. Un número cada vez mayor de educadoras y educadores europeos que reivindican ser antirracistas se muestran indignados ante los argumentos de inferioridad racial. Sin embargo, apoyan firmemente la creación de barreras para estudiantes de otras etnias, argumentando que dichos estudiantes son demasiado diferentes como para ser compatibles con las y los europeos y que no pueden mantener sus identidades étnicas sin ser asimilados.

Irónicamente, estos educadores y educadoras (Guitart, 1998) utilizan los mismos argumentos que los políticos del neofascismo europeo en auge, quienes también inciden en el reconocimiento de la diferencia en sus agendas políticas para promover la exclusión. Por ejemplo, Haider, el conocido líder del neonazismo europeo, propuso una enmienda a la Constitución austríaca alegando que Austria no es un país de inmigración. Haider no basaba sus argumentos en reclamaciones de una inferioridad racial, sino en el concepto postmoderno de la diferencia: «Si yo viviera en Estambul nadie imaginaría que cambiase mi media luna por la cruz en la escuela de mi hijo... Quienes llegan a nuestro país, a nuestro mundo, aceptarían los principios básicos de nuestra sociedad, de nuestra cultura» (Martí Font, 1993: 6).

Hoy día, en Europa las pedagogías antirracistas actualizadas deben prepararse tanto para combatir el racismo moderno como el postmoderno. La mayoría de las pedagogías carecen de recursos intelectuales para ello. Sólo la perspectiva dialógica — desarrollada por autores como Jürgen Habermas (1987a, 1987b, 1989a, 1996), Anthony Giddens (1995a, 1995b, 1996), Ulrich Beck (Beck, Giddens y Lack, 1997; Beck y Beck-Gernsheim, 1998) e incluso, por su elección racional, teóricos como Jon Elster (1998) - puede aportar un marco intelectual apropiado para combatir ambas formas de racismo. Primero debemos diferenciar el enfoque dialógico de las bases intelectuales de la discriminación contemporánea: el etnocentrismo (racismo moderno) y relativismo (racismo postmoderno).

\section{ETNOCENTRISMO DEL RACISMO MODERNO}

El etnocentrismo es la base primaria del racismo moderno. En relación a las relaciones multiculturales, las tres características principales del etnocentrismo son desigualdad, universalismo occidental y democracia capitalista.

problemas para controlar las fronteras en áreas como la que separa África de España sugieren que controlar la inmigración es una tarea difícil porque muchas personas prefieren arriesgar sus vidas a permanecer en sus países. 


\section{Desigualdad}

El etnocentrismo defiende frecuentemente la idea de la igualdad de derechos para todo ser humano, mientras de forma simultánea crea una atmósfera en la que otras desigualdades pueden crecer rápidamente. El etnocentrismo occidental define el progreso según el modelo occidental y evalúa las condiciones de diferentes personas en relación a dicho progreso. Como resultado, el racismo moderno presupone que diferentes razas tienen niveles desiguales de desarrollo intelectual, cultural, económico y político, en lugar de simplemente otros diferentes. Por ejemplo, el profesorado racista moderno piensa que los y las estudiantes payos están más motivados que los y las estudiantes gitanos porque afirman que el nivel cultural de los y las gitanas es inferior que el de los y las payas.

Esta percepción de la desigualdad racial atraviesa la mayoría de las teorías y prácticas educativas europeas. No obstante, este sesgo queda restringido al nazismo demasiado a menudo, relegando por tanto las perspectivas racistas a unos pocos discretos grupos de extremistas e individuos con visiones caducas. Muchos autores antirracistas europeos han criticado el informe Ford (Ford, 1991) por caer en este tipo de reduccionismo, desde el momento en que enfatizaba en exceso la relación entre el racismo y los grupos neonazis ${ }^{5}$. Dicho énfasis puede llevar a la incorrecta asunción de que sólo los neonazis son racistas, en vez de observar el racismo como algo más extendido, como un problema generalizado inherente a las sociedades y culturas europeas.

Para los y las educadoras, el reto de una pedagogía antirracista no se refiere tan sólo a cómo combatir el neonazismo como un peligro exterior a los colegios, sino también a cómo revisar las teorías educativas y culturales de cara a superar cualquier implicación racista. La mayoría de estas teorías etnocentristas clasifican las capacidades intelectuales de las personas como inferiores o superiores, dependiendo de su bagaje cultural. Las teorías educativas y psicológicas más extendidas a menudo sitúan a los y las estudiantes europeos en una etapa superior de desarrollo comparada con la de los niños y niñas de otras etnias. Por ejemplo, los y las profesoras dicen con frecuencia que los y las adolescentes occidentales que cursan la enseñanza obligatoria alcanzan el estadio piagetiano de las operaciones formales, mientras que las personas adultas de otras culturas que no terminaron la escuela, como muchos gitanos y gitanas, permanecen en el estadio previo, menos avanzado, de las operaciones concretas. Esta lectura representa una mala aplicación del trabajo de Piaget ya que este autor no estudió explícitamente el desarrollo adulto o el rol de la cultura en dicho desarrollo. Y, lo que es más, los y las profesoras utilizan sus investigaciones con niños y niñas de clase media blanca para aplicarlas a las familias gitanas. En consecuencia, consideran que las y los niños gitanos poseen un desarrollo intelectual inferior como resultado de su diferencia cultural. En cualquier caso, tales teorías

\footnotetext{
${ }^{5}$ Este informe fue emitido por una comisión del Parlamento Europeo en 1991.
} 
sustentan un bias creado en nombre de la diferencia y enraizado en la creencia en la desigualdad racial. Una pedagogía antirracista debería, por tanto, incluir la revisión de estas teorías así como de sus implicaciones.

\section{Universalismo occidental}

El etnocentrismo europeo acepta la idea de que personas de diferentes etnias pueden vivir en el mismo territorio, mientras rechaza la idea de la igualdad de status. Desde este enfoque, el mundo entero es un territorio único para la dominación de otras razas inferiores por una raza superior. Por tanto, los inmigrantes son tenidos en cuenta sólo para aquellas posiciones que la gente europea no quiere. El etnocentrismo mantiene, además, que la relación entre Europa y los países en vías de desarrollo debería estar basada en el intercambio de lo mejor que cada uno tiene para ofrecer y mantiene que lo mejor que pueden ofrecer las naciones en vías de desarrollo es materia prima. Por ejemplo, la alta tecnología europea puede ser intercambiada por las materias primas de estos países. Este intercambio también tiene que ver con los recursos humanos, ya que los ejecutivos y el personal europeos pueden ser exportados para ocupar altas posiciones directivas en los países no occidentales.

Tras todas estas acciones etnocentristas, incluyendo aquellas del ámbito educativo, subyace el concepto de subordinación. Las actuales políticas etnocentristas mezclan estudiantes de diferentes backgrounds en las mismas escuelas para reproducir la cultura occidental dominante. De cualquier modo, la adaptación de los niños y las niñas occidentales a una cultura escolar que generalmente reproduce la suya propia resulta más fácil que en el caso de los niños y las niñas no occidentales. A menudo, este hecho es interpretado como el resultado de su alta inteligencia y de actitudes más sofisticadas. Además, los y las educadoras occidentales conciben las escuelas de los países que consideran en vías de desarrollo como parte de unos sistemas educativos también en desarrollo que necesitan tomar como referencia los avances de Occidente. Por ejemplo, cuando los niños y las niñas africanas vienen a Europa, los colegios a menudo consideran que el hecho de que previamente hayan asistido a la escuela en sus países en vías de desarrollo es un déficit que hay que remediar.

Cuando los y las educadoras etnocentristas discuten acerca del papel de la escuela en la inclusión de las personas inmigrantes, en realidad se están refiriendo tan sólo a la inclusión de la "gente del sur» —erróneamente catalogada como personas de los países en vías de desarrollo situados sobre todo en el hemisferio sur-. En España, por ejemplo, cuando los y las educadoras etnocentristas hablan acerca de la integración de las minorías, piensan en estudiantes procedentes de Marruecos o Gambia más que en estudiantes de los EE.UU. o Alemania. Intentan asimilar personas de culturas consideradas como inferiores a la cultura europea, lo que no ocurre en el caso de los y las extranjeras del norte, quienes son tratados como iguales o superiores. 
Por ejemplo, España tiene escuelas americanas basadas en el idioma, cultura y sistema educativo dominante de los Estados Unidos. España ve con buenos ojos el desarrollo de ciertos elementos de la dominante cultura norteamericana como una contribución conveniente para sus colegios. No ocurre lo mismo con la cultura, idioma y orientaciones educativas del «sur». Las escuelas gitanas o marroquíes, que podrían enseñar de acuerdo a los idiomas y prácticas árabes y gitanos, son rechazadas. La educación, desde esta perspectiva norteamericana, es considerada como la promoción del éxito; desde la perspectiva marroquí o gitana, la educación es considerada como encerrar a los y las niñas en ghettos y como un impedimento a la integración cultural. Algunos grupos de profesores y profesoras y de familias han solicitado al gobierno español el establecimiento de cuotas restrictivas en las escuelas que mantienen el porcentaje de estudiantes considerados con "problemas para la integración» —es decir, estudiantes inmigrantes y de la comunidad gitana- en el 15\%. En este aspecto, el sistema educativo es más restrictivo que el mercado. Mientras no existen escuelas árabes en España, hay carnicerías árabes que preparan y venden carne que ha sido sacrificada de acuerdo a la tradición islámica. Sus clientes son tanto islámicos como no-islámicos que aprecian el producto. Para muchos españoles y españolas, resulta más fácil aceptar la igualdad del dinero «inferior» de algunas personas que aceptar la igualdad de sus etnias y culturas.

El modo en el que las diferentes etnias han manejado el dinero y el poder ha tenido una fuerte influencia a la hora de ser consideradas como superiores o inferiores. Las personas de las comunidades gitana, africana y árabe están subordinadas en Europa y, actualmente, incluso los y las latinoamericanas están cada vez más discriminados respecto a las personas pertenecientes a las culturas latinas europeas. De cualquier modo, la pertenencia a dichas etnias no resulta tan penosa para los individuos con dinero y poder, como los millonarios árabes, cuya presencia es bienvenida en la costa este española.

\section{Democracia capitalista}

Las y los políticos, intelectuales y medios de comunicación occidentales etnocéntricos han defendido la idea de que todas las sociedades deberían evolucionar hacia su integración dentro del sistema capitalista occidental. Han defendido las democracias siempre y cuando no han puesto en peligro sus intereses capitalistas. Argelia ofrece un ejemplo de cómo tales políticas crean conflictos y violencia entre las personas de culturas diferentes. A comienzos de los noventa,

${ }^{6}$ La aceptación de la inmigración cuando también conlleva dinero resulta clara en el caso de un inmigrante de Ghana que en 1994 ganó el mayor premio en la historia de la lotería española, casi veinte millones de dólares. El ganador fue protegido por la comunidad africana para que los medios de comunicación europeos no pudieran identificarle. Muchos de los habitantes de la ciudad que previamente se habían opuesto a la presencia de la comunidad africana desarrollaron de pronto un interés por conocerla y establecer relaciones con sus miembros. 
Argelia avanzó hacia la democracia con una creciente influencia islámica. En junio de 1990, el Frente Islámico de Salvación (FIS) ganó el 54,25\% de los votos. En diciembre de 1991 ganó la primera vuelta de las elecciones legislativas, con el $47,5 \%$ de los votos, y estaba claro que ganaría la segunda y definitiva vuelta. El gobierno, presionado por el ejército, anuló las elecciones en enero de 1992. En febrero, el ejército declaró el estado de emergencia y en marzo disolvió el FIS.

Los gobiernos occidentales nunca se opusieron a este coup d'état y la mayoría de los medios de comunicación occidentales legitimaron este proceso antidemocrático con demagógicos y efectivos argumentos (Sales, 1992). A pesar del apoyo popular al FIS, los medios de comunicación occidentales interpretaron que el $41 \%$ de abstenciones evidenciaba que sólo uno de cada cuatro votantes potenciales respaldaba al FIS. Aunque los medios occidentales no aprobaron el golpe de estado como un método legítimo de tomar el control del gobierno, aprobaron su objetivo de impedir que un partido minoritario lograra el poder. En otras palabras, en este caso el fin justificó los medios, un argumento que habría resultado inaceptable para los medios de comunicación occidentales si hubiese sido aplicado a las democracias occidentales. Tampoco habría sido aplicado en un país árabe si el ganador de las elecciones hubiese sido un partido pro-Occidente. En su defensa del golpe de estado, los medios de comunicación occidentales explicaron que la democracia no puede ser gobernada por un partido religioso, ignorando el hecho de que tal argumento jamás sería aplicado a los partidos cristianos, como el CDU alemán, gobernando las democracias occidentales. Estos capitalistas aceptan los partidos religiosos en los gobiernos democráticos cuando son cristianos, pero no cuando son islámicos.

Los medios occidentales culparon también a los islamitas por la situación violenta que emergió tras la destrucción del proceso democrático por el golpe de estado (Bell Jelloun, 1997). Tales interpretaciones sesgadas pueden llevar a los ciudadanos de a pie de los países occidentales a percibir las culturas árabe e islámica como inherentemente antidemocráticas, en vez de verlas como simplemente opuestas a los antidemocráticos defensores del etnocentrismo occidental. Esta idea demagógica genera racismo en contra de las personas y la cultura islámica en las relaciones internacionales, así como también dentro de las escuelas. En consecuencia, muchos niños y niñas europeos identifican a sus compañeros y compañeras de clase de religión islámica como terroristas fundamentalistas.

\section{EL RELATIVISMO DEL RACISMO POSTMODERNO}

El racismo postmoderno rechaza los presupuestos etnocentristas del racismo moderno argumentando que las culturas no son inferiores o superiores; son simplemente diferentes. De cualquier modo, niega las posibilidades de diálogo entre culturas diferentes con el objetivo de establecer normas comunes para la 
convivencia en territorios compartidos. En este sentido, una perspectiva racista postmoderna rechaza el que las personas árabes vivan en los países europeos. El racismo postmoderno tiene una base intelectual en los enfoques relativistas de los autores postestructuralistas, como el postmodernista Jean François Lyotard (1984), la genealogía de Michel Foucault (1988) y el deconstruccionismo de Jacques Derrida (1989). Estos enfoques están basados en los trabajos de Friedrich Nietzsche (Habemas, 1989a). Respecto al tema de las relaciones multiculturales, estos pensamientos neonietzscheanos legitiman las tres características principales del racismo postmoderno: diferencia, poder y rebelión contra el racionalismo y la democracia ${ }^{7}$.

\section{Diferencia entre las etnias}

El relativismo está basado en la noción de la diferencia. Considera las etnias o las culturas no como superiores o inferiores unas a otras, sino como diferentes. Los y las relativistas niegan tanto la perspectiva etnocentrista de la desigualdad entre las razas como la afirmación de la igualdad entre los seres humanos, las etnias y las culturas. El concepto deconstruccionista de la diferencia, como se entiende en los escritos de Derrida (1989), rechaza cualquier valoración que intente clasificar un contexto como mejor que otro: por tanto, está directamente relacionado con el relativismo. Al mismo tiempo que reivindica el radicalismo antietnocéntrico, la perspectiva deconstruccionista legitima en realidad las desigualdades sociales entre y dentro de las diferentes culturas.

El pensamiento neonietzscheano, puesto que está fundamentado en el deconstruccionismo de Derrida, tiene resultados ambivalentes respecto al racismo. Por una parte, su énfasis en la diferencia puede arrojar luz sobre cómo las instituciones y pensamientos occidentales excluyen otras etnias y culturas ${ }^{8}$. Por otra parte, la diferencia sin igualdad puede destruir las posibilidades de diálogo entre culturas diferentes. Donde existe la diferencia sin igualdad, las culturas sólo pueden ser entendidas dentro de sí mismas y el mestizaje implica la pérdida de identidad.

Por ejemplo, la cultura gitana han evitado frecuentemente que las adoles-

Hay una tendencia a incluir cualquier pensamiento neonietzscheano bajo la etiqueta del postmodernismo. De cualquier modo, en un sentido más restringido, la genealogía de Foucault y el deconstruccionismo de Derrida difieren del postmodernismo desarrollado por Lyotard en las ciencias sociales.

${ }^{8}$ Los conceptos de Derrida de diferencia y deconstruccionismo operan dentro del contexto del racismo y del antirracismo. Derrida (1989) desarrolló el concepto de différance, un neologismo que difiere de la palabra francesa différence. El cambio de la letra «e» por la letra «a» es perceptible gráficamente pero no oralmente. Existe entonces una preferencia derridiana por escribir contra el fonocentrismo, lo cual en Derrida está relacionado con el logocentrismo. Différance tiene un doble significado: diferir en espacio y diferir en tiempo. Cualquier sentido es generado por el espacio y tiempo de esta différance. 
centes acudan a la escuela porque su tradición contempla un papel clave de las mujeres dentro de la familia, que comienza en la adolescencia. Desde la postura relativista, podría argumentarse que no debería esperarse que la comunidad gitana se adhiera al concepto europeo de igualdad de derechos educativos entre hombres y mujeres. Centrándose en la diferencia cultural, los y las relativistas deconstruyen el principio de la igualdad. Consideran la escuela como una institución educativa europea impuesta a la comunidad gitana a través del etnocentrismo. La igualdad de género es, por tanto, presentada como una imposición europea en vez de como un derecho humano básico. Esto permite a los y las relativistas deconstruir el derecho universal a la escolarización, argumentando que, en otro tipo de actividades educativas, la escuela presiona a los y las gitanas a perder su identidad, cultura y modo de vida.

Este tipo de análisis se centra en los aspectos negativos de la escolarización e ignora los positivos. Por ejemplo, muchas mujeres gitanas, insatisfechas con los roles que les han sido tradicionalmente impuestos (Wang et al., 1990), utilizan la escuela para poder tener opciones profesionales que antes les resultaban inaccesibles. Del mismo modo, muchas mujeres occidentales rechazan las limitaciones preceptivas de los roles femeninos tradicionales de la cultura occidental. Sin embargo, para los y las relativistas, estas oportunidades educativas son una evidencia de la destrucción de la cultura gitana en vez de un signo de su evolución a través del cambio.

Contrariamente a lo que los y las relativistas sugieren, las perspectivas emancipadoras no son simplemente principios occidentales impuestos a otras etnias bajo la bandera del universalismo. Por el contrario, son la consecuencia natural de las luchas y sueños de las personas que, respecto a la cultura y la etnia, se afanan constantemente por mejorar sus vidas y sociedades. La relación entre las perspectivas emancipadoras de la cultura occidental y las de la gitana no es tan sólo el efecto de una imposición etnocentrista de la primera sobre la segunda, sino también un resultado del diálogo y la solidaridad entre ellas.

\section{Poder}

El relativismo defiende el poder como instrumento para regular las relaciones humanas. El pensamiento neonietzscheano considera el poder como algo creativo en vez de negativo (Foucault, 1975; Levy, 1977). En Surveiller et punir: Naissance de la prison, por ejemplo, Foucault (1975) argumenta que «debemos cesar de una vez por todas de describir el poder en términos negativos; "excluye”, "reprime”, “censura”, “abstrae”, "enmascara”, "encubre”. De hecho, el poder produce; produce realidad; produce dominio de los objetos y los rituales de la verdad. El individuo y el conocimiento que puede obtenerse de él pertenece a esta producción» (p. 196). Desde esta perspectiva, los y las relativistas entienden la sociedad como un espacio de lucha entre fuerzas opuestas. Oponen las soluciones dialógicas a la violencia — por ejemplo, acuerdos de paz y conciliación 
como una solución a la guerra- porque las relaciones culturales son percibidas como inherentemente violentas? .

Desafortunadamente, mucha gente no es consciente de que esta forma de neonietzscheanismo no busca lograr una mejora de la convivencia a través del diálogo y el consenso; en cambio, busca justificar la violencia en las relaciones entre las culturas. Las y los críticos relativistas pueden entonces justificar las dictaduras opresoras que controlan a través de la violencia directa en vez de a través del diálogo. Utilizando este tipo de perspectiva, es posible deconstruir la intervención internacional contra el nazismo en los cuarenta y la actual solidaridad internacional con las personas que sufren el hambre y la guerra como actuaciones negativas en vez de positivas.

En Europa, el tema de la intervención internacional para parar la guerra fue un debate clave durante la guerra de Bosnia. La mayoría de los y las españolas presionaron a las Naciones Unidas para mantener su labor de defender la ciudad de Srebenica de la agresión de los Chetniks serbios. En oposición a esta solidaridad, los y las autoras relativistas deconstruyeron las demandas de protección calificándolas de universalismo occidental. Srebenica fue tomada en medio de escenas de terror ante los pasivos soldados de la ONU ${ }^{10}$.

Autores relativistas escribieron contra esas intervenciones internacionales orientadas a sustituir la violencia por el diálogo. Algunos incluso defendieron el derecho de las personas a hacer la guerra y se posicionaron contra los derechos humanos como una imposición occidental. Desafortunadamente, muchas de las acciones del Año Europeo contra el Racismo estuvieron parcialmente orientadas por estas ideas relativistas. Por ejemplo, durante ese año se celebró en Barcelona una exposición titulada "La Ciudad de la Diferencia». Irónicamente, la planificación de la exhibición fue encargada a un antropólogo relativista que escribió contra los derechos humanos y a favor del derecho a la guerra (Delgado, 1994).

\section{Rebelión contra el racionalismo y la democracia}

Históricamente, las y los europeos han presenciado que las críticas radicales a las democracias occidentales y al racionalismo dejan las puertas abiertas al

9 Nietzsche (1887/1956) considera «the coming of democracy, of peace arbitrage instead of wars [and] of women rights equality» (la llegada de la democracia, del arbitraje pacífico en vez de las guerras [y] de la igualdad de derechos para las mujeres) (pp. 290-291) como factores de una identidad que declina.

${ }^{10}$ Mientras reconozco que este episodio podría ser visto como sensacionalismo, no deberíamos cerrar nuestros ojos al sufrimiento humano que la indiferencia relativista legitima. Un superviviente en Srebenica narró la lucha de una madre para salvar a su hijo de 14 años de los soldados serbios (Estarriol, 1995): «Frente a ellos, en una casa, soldados de la ONU se quedaron mirando. Vieron cómo un Chetnic... cortaba la oreja del niño. El niño comenzó a retorcerse y gritar de dolor, mientras la sangre le caía por sus hombros... el soldado atacó con su cuchillo de nuevo y la nariz del niño voló... El niño cayó al suelo, retorciéndose y gritando. De pronto su madre se lanzó hacia el Chetnik, tomó la mano del soldado que sostenía el cuchillo y lo hundió en su propio corazón» (p. 4). 
extremismo. Por ejemplo, en los años treinta y cuarenta, la filosofía intelectual radical del nietzscheanismo heideggeriano estaba ligada al nazismo alemán y al fascismo italiano. Algunos autores y autoras mantienen que esta relación es intelectualmente irrelevante porque fue una simple bastardización del pensamiento nietzscheano por parte de políticos como Hitler para justificar sus propias agendas políticas. De hecho, esta unión fue realizada por el propio Heidegger, el más importante de los nietzscheanos de la edad moderna.

En los círculos radicales existen reticencias a reconocer cualquier asociación de importantes intelectuales radicales con el nazismo. Muchos seguidores y seguidoras de Nietzsche y de Heidegger han etiquetado a quienes se atreven a relacionar los trabajos de Heidegger con el nazismo como no-intelectuales y nointeligentes (Farias, 1989). Frecuentemente, el nazismo es erróneamente reducido a dictadores políticos, jefes militares brutales y trabajadores culturales clásicamente conservadores, en vez de relacionarlo con las acciones de los y las intelectuales. Una categorización tan simple oscurece puntos relevantes para detener la creciente ola de neonazismo y su relación con el racismo postmoderno. Esta falta de un análisis científico serio deja las puertas abiertas a modas intelectuales como la neohistórica negación del Holocausto ${ }^{11}$.

Contrariamente a las creencias populares, el fascismo no fue iniciado por políticos conservadores como una acción burguesa, sino por intelectuales radicales y movimientos antiburgueses ${ }^{12}$. Antes de fundar el movimiento político fascista en Italia, Mussolini no era un político conservador, sino un radical profesor de escuela y un líder socialista. Como director de revistas y periódicos, tales como Avanti (la publicación oficial del Partido Socialista Italiano), era considerado un intelectual radical. Fue deslumbrado por la irracionalidad del futurismo, un movimiento artístico que clamaba por la destrucción de cualquier resto del pasado, incluyendo los museos, para los pintores italianos libres,

${ }_{11}$ Desde 1986, el debate intelectual ha sugerido que el nazismo fue una reacción al estalinismo. Como resultado, la "verdad" del genocidio nazi ha comenzado a ser negada por algunos sectores de la población. En Alemania, neohistoricistas proponen restaurar la narrativa y combatir lo que ven como el artificio de la explicación teórica (Habermas, 1992). Esta perspectiva hace imposible juzgar cualquier práctica fuera de su contexto particular. Dicha perspectiva deconstruccionista podría liberar a ciertos individuos, colectivos y países de su responsabilidad y culpa por haber colaborado con los nazis. Ernst Nolte (1995), el autor que inició esta revisión histórica también argumenta que no hay relación entre el trabajo de Heidegger y las implicaciones nazis de su vida. Como resultado de este debate revisionista, en los noventa, más y más personas han cuestionado la posibilidad de verificar el genocidio en los campos de concentración de Hitler. Unos pocos autores simplemente lo niegan, niegan la existencia de verdades científicas históricas (Nolte, 1995). El aumento de dicho revisionismo ha sido tan fuerte que algunos países están intentando parar sus consecuencias sociales. En 1992, por ejemplo, Austria aprobó una decisión que condena a aquellas personas que niegan o justifican el Holocausto con una pena de prisión de hasta diez años. Otros países han establecido también penas similares. En España, la sentencia está entre uno y dos años.

${ }^{12}$ En su reciente estudio en profundidad, Maia Asheri, Zeev Sternhell y Mario Sznajder (1994) perfilaron las tres fuentes del fascismo: el futurismo de Marinetti, el unionismo revolucionario comercial de Sorel y el nacionalismo tribal de Barrès. 
escritores y artistas contrarios a una tradición limitadora. El futurismo fue uno de los componentes clave del fascismo.

En Europa, los y las educadoras antirracistas no deberían adherirse al socavamiento nietzscheano y heideggeriano de las bases racionalistas de la cultura occidental y de la democracia conservadora porque, al hacerlo, promueven la irracionalidad del racismo nazi. Las escuelas, institutos y universidades deberían enseñar que la democracia actual no es sólo el resultado de una imposición de la élite en el poder, sino también de una lucha arraigada en el tiempo. Por ejemplo, las y los estudiantes deberían aprender que la gente popular, como los sans culottes de la Revolución Francesa, lucharon por la democracia. Aunque estuvieron eventualmente oprimidos por los intereses de la democracia capitalista, su situación mejoró comparada con la que vivían bajo la monarquía absoluta. Como educadores y educadoras radicales, deberíamos orientar nuestras críticas a la democracia capitalista en la consecución de una democracia mejor, en lugar de hacerlo desde una perspectiva nihilista que deja las puertas abiertas a las alternativas antidemocráticas.

\section{LA CONVIVENCIA DESDE LA PERSPECTIVA DIALÓGICA}

Desde la perspectiva dialógica, es posible crear las condiciones que permitan a la gente de diferentes culturas y etnias convivir juntas. En el ámbito de la educación, la perspectiva dialógica fue originariamente desarrollada por Paulo Freire $(1970,1997 a, 1997 b)$. De manera similar, los avances de las dos últimas décadas en las ciencias sociales se han movido, más o menos directamente, hacia esta orientación (Beck y Beck-Gernsheim, 1998; Giddens, 1995a; Habermas, $1987 a$ ). En cuanto a las relaciones multiculturales, las tres características principales de la perspectiva dialógica son la igualdad de las diferencias, los territorios compartidos y la radicalización de la democracia.

\section{Igualdad de las diferencias}

Al igual que el relativismo, la perspectiva dialógica considera las culturas y etnias no como superiores o inferiores unas a otras, sino como diferentes. Sin embargo, a diferencia del relativismo, la perspectiva dialógica pone el énfasis en la necesidad de igualdad de derechos entre etnias, así como entre los diversos sectores sociales y personas. Tiene como objetivo promover la transformación hacia principios como la igualdad y la libertad. Bajo este punto de vista, la diferencia es simplemente parte de la igualdad - el mismo derecho para todos y todas a vivir de una forma diferente.

El enfoque dialógico pretende conseguir una posición igualitaria para todas las etnias, grupos e individuos. En educación, el reconocimiento de la diferencia es importante a la hora de dirigir la diversidad cultural en las escuelas y la igualdad es importante para posibilitar que cualquiera pueda adquirir las competen- 
cias que le permitan superar sus actuales barreras sociales. Por tanto, la diferencia es necesaria para promover el mantenimiento y desarrollo de la propia identidad y cultura; de la misma forma, la igualdad es necesaria para prevenir la marginación y exclusión.

Esta perspectiva trasciende el entender la cultura en base a una nostalgia conservadora por una cultura uniforme y homogénea que, en realidad, nunca existió. La orientación hacia el diálogo y el mestizaje, o hibridad, son metas que funcionan porque ninguna cultura en Europa puede sobrevivir sin comunicarse con otras culturas, tomando elementos de ellas y desarrollando nuevos componentes culturales a partir de este intercambio. De hecho, la nostalgia conservadora por la cultura e identidad «originales» distorsiona la historia, negando que las actuales identidades humanas son el resultado de este proceso. En último término provoca racismo y rechazo al diálogo con otros, considerando este último como un peligro para la identidad original de la cultura. Hermann Tertsch (1993) escribe sobre una mujer de 91 años que siempre ha vivido en el mismo pueblo, Samorin, pero que ha pertenecido a diferentes países. Nacida en el Imperio Austro-Húngaro, primero fue húngara. Después, durante el régimen de Hitler, fue eslovaca. En 1945 se convirtió en checoslovaca y ahora es de nuevo eslovaca. Se ha visto obligada a estos cambios de identidad porque estaba demasiado ocupada trabajando para no pasar hambre como para participar en los grandes acontecimientos históricos de la región. Su historia ilustra que la construcción social de la identidad étnica y nacional puede distorsionar la historia cuando ignora a los individuos.

Cada cultura es el resultado de diferentes mestizajes y no puede evolucionar sin otros nuevos. Normalmente, los mestizajes han evolucionado bajo el dominio y la opresión de unas culturas sobre otras, pero la postura de la igualdad de las diferencias, dentro de esta perspectiva dialógica, solicita mayores condiciones de diálogo igualitarias y más libres como foro para un nuevo tipo de comunicación entre culturas y el desarrollo de nuevos tipos de mestizaje.

Una pedagogía antirracista actualizada, como la de Freire, afirma que las escuelas pueden realizar grandes contribuciones a la promoción de la idea dialógica del mestizaje. Por una parte, las escuelas sirven a las personas de diferentes etnias y culturas. Por la otra, están presionadas por las dominantes demandas culturales de la sociedad. Como instituciones etnocéntricas, las escuelas tienden a la homogeneidad y la exclusión de diferentes culturas, pero la intercomunicación de los y las profesores, estudiantes, padres y comunidades puede llevar al desarrollo de procesos dialógicos en su seno, para orientarlas hacia la igualdad de las diferencias.

En España, por ejemplo, el proyecto de Comunidades de Aprendizaje está dirigido al desarrollo de dicho proceso dialógico. El proceso de transformar las escuelas en comunidades de aprendizaje consiste en la reelaboración de un proyecto de aprendizaje de la escuela (incluyendo el currículum, organización y las normas de la institución) a través del diálogo y la participación de toda la comunidad — profesores y profesoras, padres, familiares, asociaciones, volunta- 
rios y voluntarias y compañías locales-. Como parte de esta transformación, toda la comunidad diseña un proceso dialógico coordinado en diferentes ambientes (clases, casas, calles) que incrementa las dos dimensiones del aprendizaje dialógico: el proceso de aprendizaje académico y el proceso de aprender a convivir pacíficamente.

Dicho enfoque afronta el reto cultural de combatir el racismo moderno y el postmoderno. Las comunidades deberían tener la posibilidad de aprender y experimentar cómo la comunicación entre las culturas enriquece a todas ellas y cómo es tanto posible como beneficiosa la convivencia en un territorio compartido. Los y las estudiantes deberían tener la posibilidad de verse a sí mismos no como superiores o inferiores, sino como diferentes; no como homogéneos, sino como iguales.

\section{Territorios compartidos}

Una perspectiva dialógica está orientada hacia la creación de condiciones para la convivencia entre todas las personas de diferentes culturas y etnias. Estas condiciones no están predeterminadas, debiendo ser continuamente consensuadas por los y las participantes. El diálogo y el consenso son los criterios procedimentales para la convivencia (Habermas, 1987a, 1987b, 1990, 1996, 1997), mientras que la imposición y la violencia directa están excluidas de este proceso. Las posiciones desiguales en el diálogo son retadas por el relevante disenso y la acción social. Por tanto, el proceso comunicativo o dialógico incluye el consenso para crear condiciones para la convivencia y el disenso para criticarlas cuando se necesitan condiciones nuevas y más igualitarias (Habermas, 1992).

La perspectiva dialógica reta la noción de territorio como la propiedad exclusiva de una etnia, origen, religión, cultura, lengua o patria. Habermas (1989b) propone la superación de esta vieja noción de patriotismo desarrollando en su lugar un patriotismo de constitución basado no en el territorio, sino en el acuerdo. En vez de orígenes raciales, esta perspectiva cree en las normas de consenso para organizar la convivencia entre diferentes personas.

La crítica postmoderna a la idea de diálogo considera que en el consenso siempre ganan los argumentos de quienes tienen el poder. En los consensos entre diferentes culturas, por ejemplo en torno a los derechos humanos, se impone la cultura occidental.

Desde una perspectiva dialógica se reconoce que eso es generalmente así, pero se puntualiza que en las relaciones entre personas o grupos con diferente poder son preferibles las que se basan en el diálogo entre ellas que las que se basan en la imposición directa de los más poderosos. Por ejemplo, es mejor renegociar la Declaración Universal de los Derechos Humanos mediante un diálogo y consensuadamente entre todas las culturas a que USA utilice su ejército para imponer a los demás su propia Declaración.

No obstante, hay que reconocer que, incluso en la situación ideal de habla, 
quienes son más hábiles o están más acostumbrados a argumentar tienden a influir más que el resto. Por eso, el ideal dialógico no es la última de las utopías, sino una perspectiva de cambio que, según se vaya consiguiendo, dará lugar a nuevas contradicciones y a otras utopías que las superen.

Dentro de la realidad multicultural europea, las personas gitanas han promovido históricamente este enfoque comunicativo, como se refleja en su visión de los territorios compartidos. Muchos gitanos y gitanas se consideran a sí mismos un pueblo sin territorio y sin ninguna intención de poseer nunca uno homogéneo y exclusivo. Quieren compartir el territorio con todas y cada una de las personas del mundo (Presencia Gitana, 1991), una reivindicación que realizaron a través de un documento público a mediados de los setenta. Como consecuencia de la transición política de la dictadura franquista a la democracia, España se reorganizó en diecisiete comunidades autónomas, cada una de las cuales avanzó en la definición de su propia identidad. En aquel momento, algunos gitanos y gitanas pidieron una decimoctava comunidad sin territorio. En 1993, Glyn Ford, presidente de la Comisión Parlamentaria Europea sobre Racismo y Xenofobia, se hizo eco de este concepto gitano de la no territorialidad en relación a las relaciones europeas. Se dio cuenta de que la Unión Europea tenía un país más, aparte de los oficialmente reconocidos —el no reconocido "país de los y las inmigrantes", que no tiene territorio exclusivo, tampoco busca uno y comparte la tierra con otros países europeos.

En oposición al racismo y el neonazismo que están en alza hoy día, muchas agencias humanitarias y organizaciones sociales están reivindicando una Europa intercultural y pluricultural que sea compartida por todas y cada una de las personas que vivan en ella. Es un llamamiento para que las diversas personas convivan de acuerdo a una serie de normas básicas acordadas por todos y todas. Por ejemplo, el 7 de febrero de 1993, veinte mil personas se manifestaron en París en favor de una Francia multiétnica. Entre ellas había hombres y mujeres africanos, árabes, judíos, europeos en general y personas de muchas otras etnias reivindicando un territorio donde poder mantener, desarrollar y compartir sus propias diferencias, culturas e identidades. Muchos bailaron al son de "Todos somos descendientes de inmigrantes».

La educación europea requiere un multiculturalismo que incluya tanto las soluciones pluriculturales como las interculturales ${ }^{13}$. Las primeras son necesarias

13 Aunque el multiculturalismo europeo tiene varias definiciones, generalmente se entiende (Castells et al., 1994) como el reconocimiento de la existencia de diferencias culturales en el mismo territorio. El interculturalismo es una intervención dentro de esta realidad que pone el énfasis en la relación entre culturas. El pluriculturalismo es otra intervención que se centra en el mantenimiento de la propia identidad. La educación intercultural promueve la coexistencia en la misma escuela de personas de diferentes etnias, mientras que las escuelas basadas en una cultura tienden a ser vistas como guettos. La educacion pluricultural tiende a dar más valor a la posibilidad de que los y las estudiantes sigan una educación que facilite el mantenimiento y desarrollo de su propia cultura. Por ejemplo, la idea de una escuela gitana en Barcelona sería vista como una solución guetto desde una perspectiva intercultural y como una oportunidad para la identidad cultural desde una perspectiva pluricultural. 
para permitir a todos los individuos y grupos el respeto a sus diferencias; las segundas son necesarias para brindarles la posibilidad de intercambiar y compartir nuevas formas de vivir y nuevos mestizajes culturales con otros. Tanto la educación pluricultural como la intercultural pueden darse en territorios compartidos. Por ejemplo, una escuela basada en la cultura gitana para quienes deseen poner el énfasis en sus diferencias podría existir junto con otros proyectos escolares basados en el intercambio cultural.

\section{Radicalización de la democracia}

La creación de una opción dialógica crítica para la democracia (Giddens, 1995a, 1996) implica la comprensión y la aplicación radical de los principios de igualdad y libertad. Esta alternativa también significa la superación de cualquier tipo de exclusión por razones de cultura, religión, lengua o estilo de vida.

El etnocentrismo del racismo moderno identifica la democracia con las democracias occidentales, las cuales están limitadas por su interés en el capital. En cambio, la posición dialógica crítica es un reto a todas las limitaciones a la democracia y promueve la negociación intercultural en torno a los principios únicos de igualdad de derechos para todos y todas.

El relativismo del racismo postmoderno deconstruye el concepto de democracia. Afirmando la no superioridad de unos valores sobre otros, desde esta perspectiva, uno podría afirmar que la democracia no es superior a la dictadura. Dicha posición deja la puerta abierta a quienes imponen sus creencias haciendo uso de la violencia. En contraposición, el enfoque dialógico crítico no deconstruye la democracia. Por el contrario, busca extender y radicalizar la democracia.

Las diferencias en las interpretaciones de la democracia entre los y las etnocentristas, relativistas y las perspectivas dialógicas pueden observarse en los recientes conflictos en Argelia. En enero de 1995, la oposición política de Argelia - compuesta por el Frente Islámico de Salvación (FIS), el partido más influyente en Argelia; el laico Frente Nacional de Liberación y otros grupos- se reunió en el exilio. Estos colectivos propusieron un «acuerdo nacional» consensuador al gobierno de Argelia basado en los principios de sufragio universal, multipartidismo, alternativas políticas y el rechazo a la violencia. Sus acciones reflejaron un enfoque dialógico ante un conflicto político.

En respuesta, el pensamiento dominante etnocentrista del actual régimen de Argelia se opuso a dicho consenso. Cuando las elecciones dieron la victoria al FIS, el régimen utilizó el ejército para detener el sufragio universal con la violencia. Hicieron esto para reducir la democracia en Argelia, excluyendo la posibilidad de un gobierno islámico. Para justificar sus acciones, utilizaron el argumento relativista del derecho de los pueblos a hacer la guerra. También instrumentalizaron el hecho de que la oposición política se hubiese reunido en un país occidental como prueba de la interferencia extranjera. El líder del FIS, 
Abdelkader Hachani, sin desear la interferencia extranjera, trabajó por el diálogo con las democracias occidentales. Pidió el apoyo de la Unión Europea para impulsar una solución política basada en el diálogo entre los y las argelinos (Azcárate, 1998). Haciendo esto, estaba utilizando una orientación dialógica para construir una alternativa a la democracia definida por el etnocentrismo europeo y para distanciarse de las propuestas relativistas que evitan el cambio cultural.

La evolución de Argelia es crucial para las relaciones entre europeos y árabes en ambos lados del Mediterráneo. La subordinación etnocentrista de la democracia como un instrumento de defensa del islamismo, así como el deconstruccionismo relativista de la democracia en favor de la afirmación de las identidades tradicionales, implica poner en peligro la paz mundial. Ambos enfoques promueven la posibilidad de una guerra entre etnias, culturas y religiones. También señalan la destrucción de las soluciones democráticas.

Estos conflictos no se limitan al ámbito político. Los medios de comunicación occidentales transmitieron estas ideas y símbolos, que crearon obstáculos a la extensión y radicalización de la democracia. Por ejemplo, los niños y niñas y los educadores y educadoras son diariamente bombardeados por la aceptación pública de la guerra étnica y de una democracia limitada. Los cómics, la música, la televisión e incluso la literatura infantil incorporan símbolos de las guerras étnicas y del neonazismo ${ }^{14}$. Este proceso traslada la percepción pública de la guerra y el nazismo de la terrible realidad al espectáculo provocador. Incluso los y las educadoras que son favorables a la paz están cada vez más influenciados por la relativista negación de la cruda y destructiva realidad de las guerras y el nazismo. Esta transformación permite a los y las intelectuales postmodernos discutir acerca de la guerra simplemente como una representación, como en el libro de J. Baudrillard, La guerra del Golfo no ha tenido lugar (1991).

La teoría representacional postmodernista socava, por tanto, las bases racionalistas de la democracia. Sirve para negar la realidad del exterminio nazi en los campos de concentración, para aceptar las implicaciones antidemocráticas de determinados intelectuales y sus teorías como irrelevantes e incluso para presentar a los líderes fascistas como excepcionales personas. Por ejemplo, en 1994 en Italia, Silvio Berlusconni, el líder político cuya carrera estaba basada en la industria de las telecomunicaciones en vez de en las ideas, lideró el gobierno como cabeza del partido derechista Forza Italia, con el apoyo del neofascista Alleanze Nazionale. Durante la campaña electoral, el canal de televisión RAI-2 difundió una serie sobre el joven Mussolini. La imagen que retrató de este líder era más atractiva que la imagen de terror que la mayoría de la gente tenía pre-

${ }_{14}$ De cualquier modo, existe una resistencia a estos símbolos destructivos que sugiere las posibilidades transformadoras de la acción humana. En abril de 1992, en nuestro país, por ejemplo, un grupo de estudiantes de sexto grado del Colegio Federico García Lorca denunciaron Kabuto, una serie de dibujos animados de televisión, porque sus héroes vestían la esvástica. Esta iniciativa dio como resultado la decisión del canal de televisión de interrumpir la emisión de dicha serie. 
viamente asociada con el fascismo. Las y los espectadores vieron un Mussolini asociado con las emociones humanas más que con el horror. A los ojos de muchos niños y niñas, la imagen ficticia y romántica del joven Mussolini en la televisión es mucho mejor que la imagen de los líderes políticos democráticos retratada por los medios del país.

En un momento en el que se da un dramático crecimiento del nuevo racismo y del neonazismo, una pedagogía antirracista actualizada debería desarrollar una oposición intelectual a las bases culturales del fascismo. No debería equiparar las críticas radicales a la democracia actual y sus raíces racionalistas con la lucha contra el racismo porque algunas de esas críticas en realidad promueven el postmodernismo radical y el neonazismo. En Europa, no podemos entender la democracia como una concesión. Las nuevas pedagogías antirracistas deberían estar presentes en todo tipo de lenguajes, incluyendo los cómics y la música ${ }^{15}$.

Las críticas dialógicas de los actuales acuerdos democráticos son parte de la lucha democrática y antirracista. Estas críticas están orientadas hacia un mayor diálogo igualitario entre las personas de diferentes etnias que viven en el mismo territorio.

\section{CONCLUSIÓN}

Dado el actual contexto sociopolítico, las instituciones educativas y los y las educadoras deben buscar formas de combatir tanto el racismo moderno como el postmoderno a través de las pedagogías antirracistas. En concordancia con las iniciativas de la Unión Europea, muchos y muchas lo están haciendo así. A pesar de estos esfuerzos, el racismo no ha dejado de crecer en Europa, lo que ha llevado a muchos educadores y educadoras a reflexionar sobre este hecho. En el proceso, están descubriendo que muchas de estas acciones están enmarcadas dentro de las perspectivas que actualmente promueven el racismo en vez de superarlo.

Una de las razones principales es que el relativismo combate el racismo moderno con propuestas y acciones que promueven el racismo postmoderno - el tipo de racismo que hoy excluye los y las inmigrantes y grupos minoritarios de un modo más deshumanizante-. Por ejemplo, el énfasis en deconstruir el diálogo y el consenso favorece a quienes argumentan que nuestras respectivas culturas e identidades estarían más seguras si los y las europeas vivieran en «nuestra» Europa y los y las árabes regresaran a «sus» países. Para evitar la ho-

15 En España, casi todos los dibujantes de cómic conocidos publicaron un libro de dibujos antirracistas (Torres et al., 1993), coordinado por la asociación gitana Presencia Gitana. El mismo tipo de trabajo está siendo desarrollado por grupos como Comilande, una asociación de jóvenes autores alemanes. También hay reacciones importantes en el mundo de la música. En 1992, un festival de rock antirracista unió 300.000 personas en Munich con el eslogan «Todos somos extranjeros». Un festival similar, celebrado anualmente en Frankfurt, reunió 100.000 personas con el eslogan «Ellos hoy, tú mañana». 
mogeneización cultural, muchos educadores y educadoras defienden las diferencias de identidad sin ser conscientes de que los líderes neonazis utilizan argumentos idénticos para sostener la idea de que grupos diferentes, etnias o razas no pueden vivir juntos dentro del mismo territorio.

La confusión de muchos educadores y educadoras entre los enfoques relativistas y dialógicos les llevan a promover el racismo postmoderno mientras combaten el racismo moderno. Debido a que ambas perspectivas se posicionan en contra del racismo moderno y sus bases etnocentristas, las y los educadores las entienden como iguales. Además, hasta mediados de los noventa, el pensamiento postmoderno era la moda intelectual en Europa. Los y las educadoras adoptaron las orientaciones relativistas del pensamiento postmoderno y las utilizaron como el marco teórico de sus prácticas. Los y las educadoras deben ser conscientes de que dicho relativismo es, en realidad, la base intelectual del racismo postmoderno. En contraposición, la perspectiva dialógica es la base intelectual para la superación tanto del racismo moderno como del postmoderno.

Las y los educadores necesitan, por tanto, incluir la perspectiva dialógica en su lucha contra la desigualdad cultural. En este sentido, podrán centrarse en la superación de la creciente ola de racismo y neonazismo en Europa. La perspectiva dialógica hace posible que las diferentes etnias, culturas, naciones y poblaciones compartan las mismas escuelas y territorios a través del diálogo. Un criterio esencial de sus pedagogías debería ser evitar las representaciones erróneas de los intelectuales nazis como héroes de las acciones antirracistas. Otro criterio debería ser alejarse de los marcos teóricos que podrían posibilitar la legitimación de comportamientos racistas, e incluso neonazis, o las formas discriminatorias. En cambio, las y los educadores deberían basar las teorías educativas y las pedagogías en trabajos que respetan los derechos humanos, la democracia, la igualdad, la solidaridad y la diferencia. Sobre la base de dichos trabajos, las y los educadores utilizarán sus teorías, acciones y creencias para unirse a la lucha de los pueblos por la convivencia en las mismas escuelas. Diferentes pero iguales.

\section{BIBLIOGRAFÍA}

Althusser, L. (1985): Para leer El Capital, México: Siglo XXI.

- (1992): El porvenir es largo: Los hechos, Barcelona: Destino.

Asheri, M.; Sternhell, Z., y Sznajder, M. (1994): El nacimiento de la ideología fascista, Madrid: Siglo XXI.

AzCÁrate, M. (1998): «Argel: Matanzas y autoridades», El País, 18 de enero, p. 6.

BAUdRILLARD, J. (1991): La guerra del Golfo no ha tenido lugar, Barcelona: Anagrama.

BECK, U., y BECK-GERNSHEIM, E. (1998): El normal caos del amor, Barcelona: Roure.

Beck, U.; Giddens, A., y Lash, S. (1997): Modernidad reflexiva, Barcelona: Península.

Bell Jelloun, T. (1997): «El silencio de los intelectuales», El País, 30 de enero, p. 11.

CÁceres, G. (1993): «Haider: El nazi elegante», El Periódico, 7 de febrero, p. 16.

CASTElls, M. (1997a): La era de la información. Vol. I: La sociedad red, Madrid: Alianza.

- (1997b): La era de la información. Vol. II: El poder de la identidad, Madrid: Alianza.

- (1998): La era de la información. Vol. III: Fin del milenio, Madrid: Alianza. 
Castells, M.; Flecha, R.; Freire, P.; Giroux, H.; Macedo, D., y Willis, P. (1994): Nuevas perspectivas criticas en educación, Barcelona: Paidós.

Contreras, J. (1994): Los retos de la inmigración: Racismo y pluriculturalidad, Madrid: Talassa.

Delgado, M. (1994): «¿Es la guerra un derecho de los pueblos?», El Periódico, 27 de julio, p. 7.

DERrIDA, J. (1989): De la gramatología, Madrid: Siglo XXI.

Descombes, V. (1987): «Je m'en Foucault», London Review of Books, March 5, pp. 20-21.

Elster, J. (ed.) (1998): Deliverative democracy, New York: Cambridge University Press.

Estarriol, R. (1995): «El horror nazi de Srebenica», La Vanguardia, 22 de julio, p. 4.

FARIAS, V. (1989): Heidegger y el Nazismo, Barcelona: Muchnik.

FORD, J. (1991): Informe Ford sobre el racismo en Europa, Madrid: Ministerio de Asuntos Sociales.

Foucault, M. (1975): Surveiller et punir: Naissance de la prison, París: Gallimbard.

- (1988): Nietzsche, la genealogía, la historia, Valencia: Pre-Textos.

FreIre, P. (1970): Pedagogía del oprimido, México: Siglo XXI.

- (1997a): Pedagogía de la autonomía, Madrid: Siglo XXI.

- (1997b): Pedagogy of the heart, New York: Continuum.

Giddens, A. (1995a): Modernidad e identidad del yo, Barcelona: Ediciones Península.

- (1995b): La transformación de la intimidad, Madrid: Cátedra.

- (1996): Más allá de la izquierda y la derecha. El futuro de las políticas radicales, Madrid: Cátedra.

Giroux, H. A., y FleChA, R. (1992): Igualdad educativa y diferencia cultural, Barcelona: Roure.

GuitaRT, J. (1998): «Enseñanza descarta el reparto de alumnos inmigrantes extranjeros entre las escuelas», El País, 31 de agosto, p. 15.

Gumuzio, J. C. (1994): «Sobre la vigencia fascista», El País, 29 de diciembre, pp. 4-5.

Habermas, J. (1987a): Teoría de la acción comunicativa. Vol. I. Racionalidad de la acción y racionalización social, Madrid: Taurus.

- (1987b): Teoría de la acción comunicativa. Vol. II. Crítica de la razón funcionalista, Madrid: Taurus.

- (1989a): El discurso filosófico de la modernidad, Madrid: Taurus.

- (1989b): Identidades nacionales y postnacionales, Madrid: Tecnos.

- (1990): Pensamiento postmetafísico, Madrid: Taurus.

- (1992): En P. Dews (ed.), Autonomy and solidarity: Interviews with Jürgen Habermas, London: Verso.

- (1996): Between facts and norms: Contributions to a discurse theory of law and democracy, Cambridge, eng.: Polity Press.

- (1997): "Multiculturalism: does culture matter in politics?», en Seminario para Profesores: Teoría de la Democracia, Departamento de Filosofía Teorética y Práctica, Facultad de Filosofía, Barcelona, 9-10 de abril.

LEVY, B. (1977): "Non au sexe roi», Le nouvel observateur, 644, March 12, pp. 92-93, 95, 98, 100, 105, 113, 124, 130.

LYOTARD. J. F. (1984): La condición postmoderna, Madrid: Cátedra.

Martí Font, J. M. (1993): «No sobrevaloro el fenómeno nazi», El País, 7 de febrero, p. 6.

Molina, F. (1994): Sociedad y educación: Perspectivas interculturales, Lleida: Edicions Universitat de Lleida.

NiETzsChe, F. (1987): La genealogía de la moral, Madrid: Alianza.

Nolte, E. (1995): Nietzsche y el nietzscheanismo, Madrid: Alianza.

Presencia Gitana (1991): Informe sobre la cuestión gitana, Madrid: Autor.

SAles, F. (1992): «El círculo Argelino», El País, 23 de enero, p. 2.

Tertsch, H. (1993): La venganza de la historia, Madrid: El País-Aguilar.

TORRES, R. (ed.) (1993): Vamos a reírnos muy en serio del racismo, Madrid: Editorial Presencia Gitana.

Wang, K.; Díaz, M. T.; Engel, M.; Grande, G.; Martín, M. L., y Pérez Serrano, M. (1990): Mujeres gitanas ante el futuro, Madrid: Editorial Presencia Gitana. 


\begin{abstract}
This article raises the subject of the increase in racism in present-day Europe and the challenges that this fact poses for education and educators. The author distinguishes between two types of racism: an old one, modern racism, and another more recent one, postmodern racism. The first is based on arguments of inequality and the existence of superior and inferior races and ethnic groups. The second maintains that ethnic groups and races are neither superior nor inferior; they are just different. It places the emphasis on the impossibility of an egalitarian dialogue between different races and ethnic groups for establishing common rules for living side by side. Despite the fact that in Europe there is an anti-racist educational tradition, educators often do not have the intellectual and educational instruments for combating this form of racism. Flecha suggests that educators have attempted to combat racism by developing antiracist teaching sciences which use the relativist focus defended by contemporary thinkers such as Michel Foucault and Jacques Derrida. The author argues that this focus implies a challenge for modern racism but that it does in fact stimulate postmodern racism. Starting from the work done by dialogic theorists like Paulo Freire and Jürgen Habermas, Fecha suggests instead that educators use the dialogic approach, which places the emphasis on the need for equality of rights for all individuals, in order to be able to develop effective anti-racist teaching sciences which can combat both forms of racism simultaneously.
\end{abstract}

